\title{
Detection of Chlamydophila pneumoniae and human herpesvirus 8 in primary cutaneous anaplastic large-cell lymphoma: a case report
}

\author{
Alessandro Borghi ${ }^{1}$, Elisabetta Caselli², Dario Di Luca ${ }^{2}$, Adolfo Sebastiani ${ }^{3}$, Paolo Perri ${ }^{3}$, Silva Seraceni ${ }^{4}$,
} Carlo Contini ${ }^{4}$ and Annarosa Virgili ${ }^{*}$

\begin{abstract}
Background: The etiology of primary cutaneous anaplastic large-cell CD30+ lymphoma is largely unknown, and although an infectious involvement has been suspected, the implication of infectious agents in its pathogenesis is still unclear.

Findings: We report the case of a HIV-negative patient referred to our hospital with a rapidly enlarging skin tumor on her upper eyelid. Surgical excision was performed and histological analysis evidenced a primary cutaneous anaplastic large-cell lymphoma. Due to the ocular localization and to the prominent angiogenic component of the lesion, molecular analyses for the detection of Chlamydophila pneumoniae and HHV8 were performed, revealing the presence of an infection by both pathogens in surgical biopsy and in peripheral blood mononuclear cells.

Conclusions: These findings suggest for the first time a possible association of C. pneumoniae and/or HHV8 infection, or both together, with primary cutaneous anaplastic large-cell lymphoma in non-immunocompromised and HIV-negative subjects. This potential pathogenic association, if confirmed, could provide potential indications for future therapy.
\end{abstract}

Keywords: Primary cutaneous anaplastic large-cell lymphoma, Chlamydophila pneumoniae, Human herpesvirus 8 , Infection-related carcinogenesis, Eyelid

\section{Introduction}

The risk factors for the development of cutaneous lymphomas are largely unknown. An infectious etiology has been suspected and investigated [1], but the implication of infectious agents in the pathogenesis of cutaneous lymphoproliferative disorders is still controversial.

Chlamydophila pneumoniae is an obligate intracellular pathogen with a worldwide diffusion and high seroprevalence in the adult population (50-70\%) [2]. Although C. pneumoniae is known to infect human keratinocytes in vitro and to be associated with some cutaneous $\mathrm{T}$ cell lymphomas (CTCLs) [3,4], its implication in the pathogenesis of skin lymphomas remains unclear.
Human herpesvirus 8 (HHV8) prevalence varies geographically [5], being significantly higher in HIV-infected patients [6,7]. HHV8 is causally related to KS and is associated to other malignancies, including Multicentric Castleman's Disease (MCD), Primary Effusion Lymphomas (PEL) and other lymphoproliferative disorders in immunosuppressed patients [8]. In vivo, HHV8 has been found in KS endothelial cells, in T and B lymphocytes, monocytes and keratinocytes, showing a broad cell tropism [9].

Here we report the case of an immunocompetent patient with a primary cutaneous anaplastic large-cell lymphoma (PCALCL) characterized by the presence of active C. pneumoniae and HHV8 infections.

\section{Case report}

A 64-year-old woman presented at our Dermatology outpatient Unit with a 6-week-history of a single, painless,
1Department of Medical Sciences, Section of Dermatology, University of

Ferrara, Via Savonarola 9, 44121 Ferrara, Italy

Full list of author information is available at the end of the article 
$26 \mathrm{~mm}$ in diameter rapidly enlarging skin tumor located on her upper right eyelid (Figure 1). The lesion was elevated, firm, of reddish-brown color, with well-defined borders and central crater-like ulcero-necrotic depression covered with crust. No ocular involvement was assessed. Physical examination was unremarkable and there was no palpable lymphadenopathy. The patient's medical history included Hashimoto's thyroiditis longterm treated with levothyroxine and chronic urticaria cyclically treated with oral antihistamine. At the onset, the lesion had been treated with aspecific systemic and topical antibiotics in the suspect of a pyodermitis, but the clinical picture worsened. The patient complained of about 2-week slight intermittent fever, sweats, and itching but without weight loss.

\section{Methods and results}

A surgical excision of the lesion was performed at the Ophthalmological Unit and histological examination revealed diffuse lymphocytic infiltration of the dermis with anaplastic lymphoid large cells (Figure 2). Tumor cells presented irregular nucleus, frequent mitotic figures, and were positive for CD3, CD2 and CD30, and negative for CD5, CD56, ALK and CD20, as determined by immunohistochemistry. The Ki67/MIB-1 proliferation index was about 90\%. BIOMED-2 molecular analysis evidenced monoclonal rearrangement of the TCR- $\gamma$ gene. Systemic evaluation including a positron emission tomography/ computed tomography scan of the body, bone marrow biopsy, complete blood count with differential, and blood chemistry including lactate dehydrogenase, showed no evidence of extracutaneous involvement. Orbital magnetic resonance imaging also gave normal results. The patient's serum was negative for anti-HIV antibodies. The diagnosis was primary cutaneous CD30+ anaplastic large cell lymphoma.

Considering the ocular localization and the histological features of the lesion, and the high potential of
Chlamydia and HHV8 in lymphoma induction, the local and systemic presence of both pathogens was investigated, after receiving informed consent from the patient. The research has been carried out in compliance with the Helsinki Declaration. Approval by the institutional review board of our Hospital was not required for the present study, as materials were not collected specifically for this study, and were completely de-identified.

C. pneumoniae was searched in cutaneous biopsy and in peripheral blood mononuclear cells (PBMCs) isolated by density gradient from peripheral blood (Fycoll-paque plus, GE Healthcare Europe GmbH, Milan, Italy). DNA and RNA were extracted as previously described [10,11], and assayed by PCR. A fraction of PBMCs was instead centrifuged, suspended in RPMI 1640 medium (Gibco, Invitrogen, Carlsbad, CA) and co-cultured up to 144 hours with Hep-2 cell line (ATCC CCL-23), to increase the number of bacterial inclusions [11]. Cultured samples were then processed as done for fresh uncultured cells. Analyses included nested-PCR and PCR after retrotranscription (RT-PCR), using primer sets targeting $16 \mathrm{~S}$ rRNA, outer membrane protein (ompA/MOMP), and HsP-60 genomic regions of C. psittaci, C. pneumoniae, and $C$. trachomatis [11]. Amplification fragments, corresponding to C. pneumoniae $16 \mathrm{~S}$ rRNA gene, were found both in tumor tissue and in co-cultured PBMCs (Figure 3). Amplicons were sequenced by ABI PRISM 377 DNA Sequencer (Applied Biosystems, The Netherlands) and compared with other Chlamydiaceae genes [12], showing a strict homology with $C$. pneumoniae TW183 strain (AE009440.1, 99\%; E value: < 0.01).

In parallel, the same specimens were also used for HHV8 search, by PCR or real time quantitative PCR (qPCR) specifically designed in three different regions of HHV8 ORF50 and ORF26 genes [10]. The analysis of three different gene segments was undertaken to avoid the risk of false positive/negative results connected with a single gene detection. Results showed that both tumor biopsy
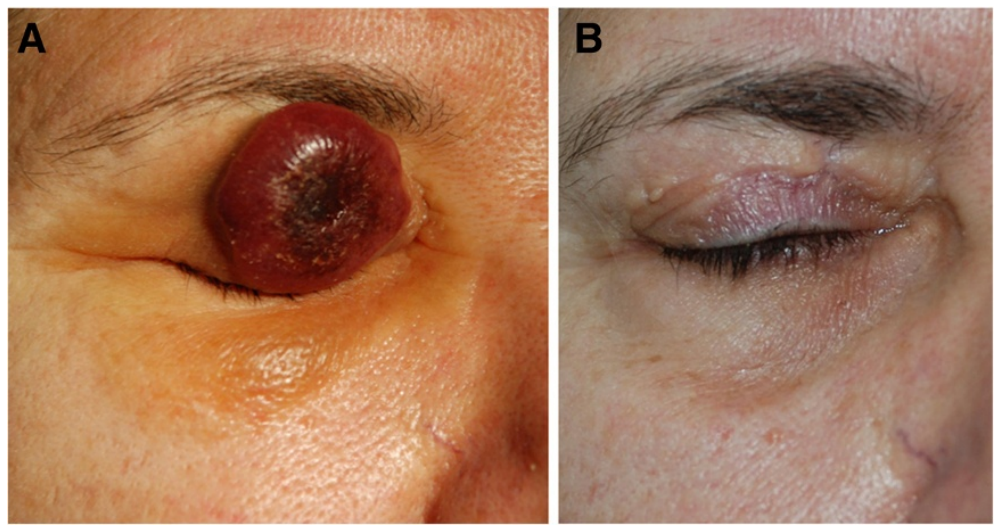

Figure 1 Clinical features. (A) The skin tumor on patient's upper right eyelid; (B) No relapse occurred 12 months after surgical excision. 

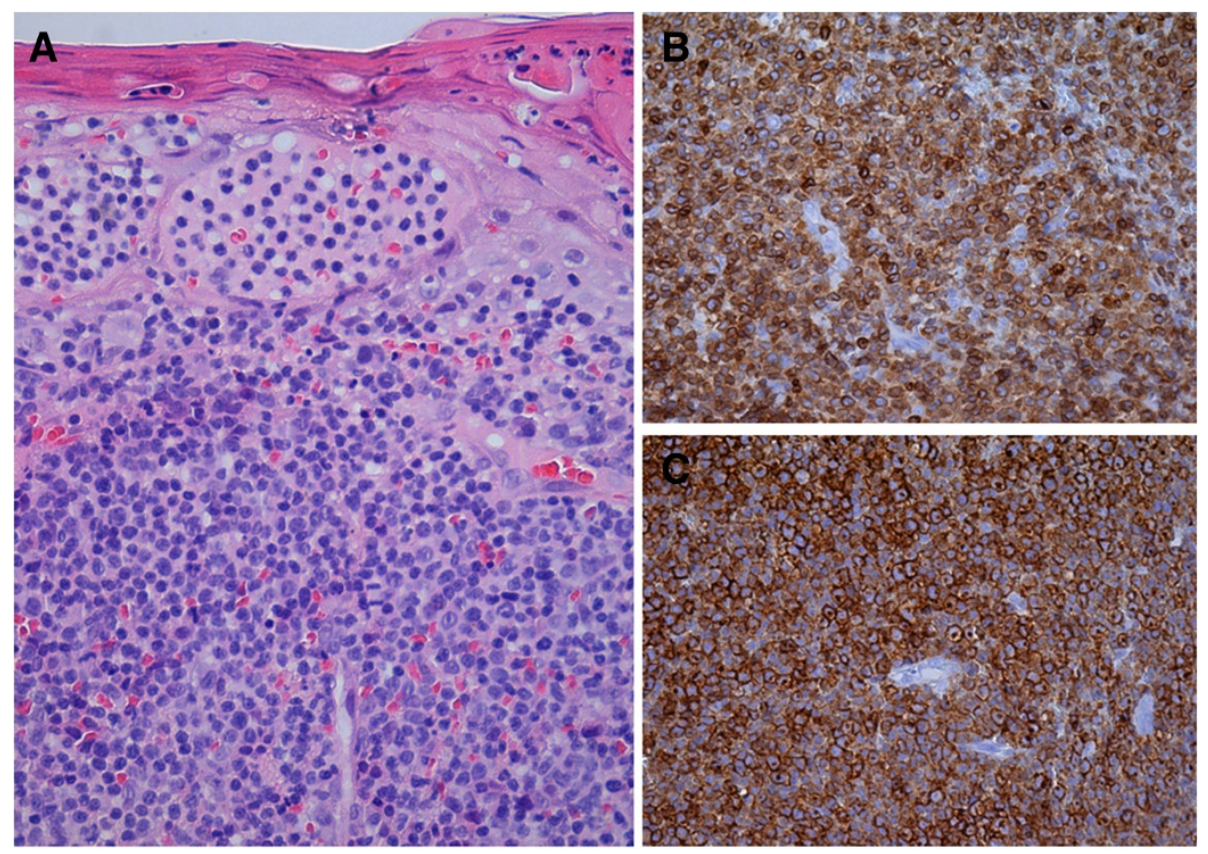

Figure 2 Histological and immunohistochemical findings. (A) Diffuse lymphocytic infiltration of the dermis predominantly composed of large pleomorphic cells with irregular nuclei and prominent nucleoli (hematoxylin-eosin staining, magnification 20x). By immunoperoxidase staining, the neoplastic cells showed marked and diffuse expression of CD3 (B) and CD30 (C).

and PBMCs harbored HHV8 sequences (Figure 4A-B). Quantification of viral load, as determined by qPCR, showed $1.24 \times 10^{3}$ virus genome copies per $100 \mathrm{ng}$ total DNA in tumor biopsy and $5 \times 10^{3}$ copies/100 ng DNA in PBMCs. HHV8 DNA was detected also in the plasma fraction of peripheral blood (Figure 4B), suggesting the presence of virions released from productively infected cells. Consistently with this, transcriptional analysis of HHV8 in PBMCs showed the presence of lytic ORF50/ ORF26 transcripts, in addition to latent ORF73 mRNA, demonstrating that HHV8 was actively replicating, as ORF50/ORF26 genes are only expressed during the productive phase of infection (Figure $4 \mathrm{C}$ ). Since EBV infection has been associated to the occurrence of ocular lymphomas, the specimens were also analyzed for the presence of EBV, by specific nested PCR, obtaining negative results.

Due to the detection of active chlamydial infection, the patient was given doxycycline $100 \mathrm{mg}$, twice a day, for 4 weeks. This treatment was safe and well tolerated, and C. pneumoniae was no longer detectable in PBMCs after the conclusion of antibiotic treatment.

Follow up analyses were performed after 12 months, during which the patient has remained free of skin and systemic disease. C. pneumoniae was no longer detectable in the patient's PBMCs, and HHV8 was no longer sustaining active infection, suggesting that the virus entered the latent phase.

\section{Discussion}

Primary cutaneous CD30+ lymphoproliferative disorders are the second most common form of CTCLs, including PCALCL [13]. PCALCL usually occur as rapidly growing and ulcerating large tumors, histologically characterized by large tumor cells with an anaplastic, pleomorphic, and immunoblastic cytomorphology, largely expressing (>75\%) CD30. In the etiology of CTCLs, a role for superantigenic activation of $\mathrm{T}$ cells leading to accumulation of skin-homing $\mathrm{T}$ cells has been suggested [14], and defects in apoptosis signalling in skin-homing $\mathrm{T}$ cells

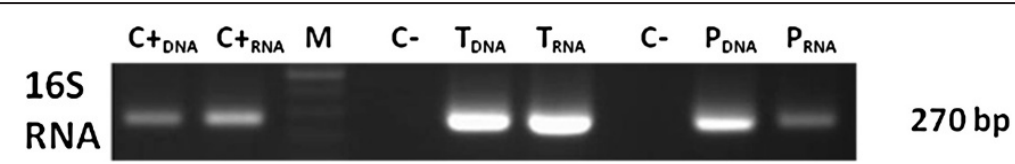

Figure 3 C. pneumoniae detection in tumor biopsy (T) and PBMCs (P). Total DNA and RNA were extracted by tissue specimen and PBMC and analyzed by PCR and RT-PCR for 16s RNA C. pneumoniae gene. Amplification controls include negative (C-) and positive controls (corresponding respectively to DNA and RNA extracted from C. pneumoniae TW183 strain); Marker 100 bp (M). 


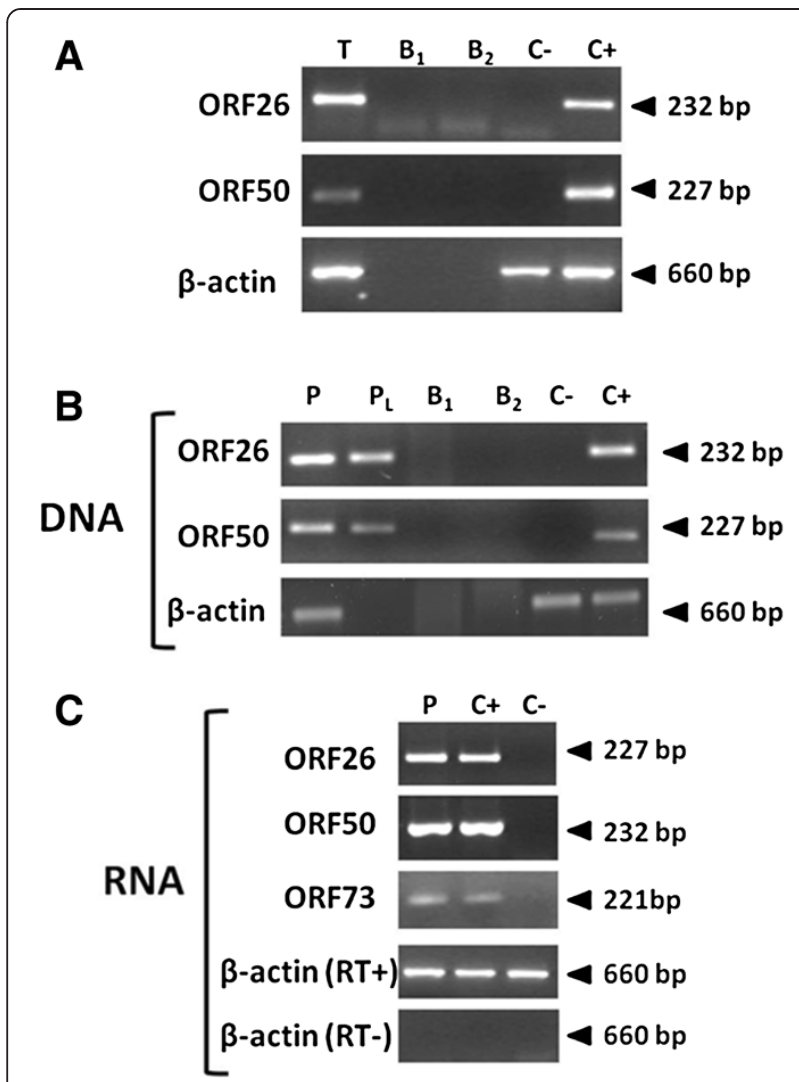

Figure 4 HHV8 presence in tumor biopsy and peripheral blood. (A) Total DNA extracted from biopsy tissue (T) was analyzed by PCR for HHV8 ORF50 and ORF26 genes. Amplification of the house-keeping $\beta$-actin gene was included as a control, and DNA from a T cell line negative for HHV8 (JJhan cells) and from a PEL-derived B cell line latently infected by HHV8 (BCBL-1 cells) were respectively used as negative $(C-)$ and positive $(C+)$ controls. Amplification controls also included: blanks of extraction $\left(B_{1}\right)$ and amplification $\left(B_{2}\right)$. (B) Total DNA extracted from PBMCs $(P)$ and plasma $\left(P_{L}\right)$ fractions were analyzed as described for tumor biopsy. (C) Total RNA extracted from PBMCs was analyzed by RT-PCR for HHV8 lytic (ORF50, ORF26) and latent (ORF73) genes. Negative ( $(-)$ and positive $(C+)$ controls, and $\beta$-actin control with (RT+) or without (RT-) previous retrotranscription are also shown.

have been hypothesized to play a role [15]. However conclusive data are still lacking.

Accumulating evidence suggests that Chlamydia Spp. may play a role in oncogenesis for their tendency to cause persistent infections and chronic antigenic stimulation. $C$. psittaci has been associated to ocular adnexal lymphomas (OALs) of MALT-type [3]. C. pneumoniae has been shown to be present in some CTCL and to induce the expansion of C. pneumoniae-specific $\mathrm{T}$ cells throughout the release of Sézary T cell-activating factor (SAF), thus potentiating the development of CTCL [4]. C. pneumoniae eradication with doxycycline has been reported to result in lymphoma regression in about a half of patients [16], as also evidenced for $C$. trachomatis, supposed to have a role in ocular lymphoma [17]. Moreover, chlamydial infection has been detected in some forms of cutaneous lymphomas and in diffuse large B-cell lymphomas arising in the Waldeyer's ring [3].

On the other hand, several viruses have been investigated as possible trigger agents of CTCLs, including herpesviruses. EBV infection was associated to extranodal NK/T-cell lymphoma and some primary cutaneous lymphomas [18]. Cytomegalovirus infection was associated with CTCLs [19], but the association is still controversial.

HHV8 was found in various tumors and lymphoproliferative diseases [8], and the incidence of HHV8related tumors, even in populations with high HHV8 seroprevalence suggests the need for cofactors [20]. A number of HHV8 genes are known to have effects in cell proliferation and transformation [8], and accumulating data point to the importance of lytic replication for the development of HHV8-associated neoplastic pathologies, as indicated by recent clinical studies [21]. Our data present evidence of a concurrent active infection by C. pneumoniae and HHV8 in a PCALCL patient, suggesting for the first time a potential association of chlamydial and HHV8 infection with the development of the PCALCL. Although the possibility exists that it might be simply accidental, the presence of both microorganisms is intriguing, and suggests that they might reciprocally potentiate their pathogenic potential. This hypothesis has been suggested for other pathologies without obtaining clear conclusions [22,23], and may deserve further investigation. In parallel, individual susceptibility might be important for the development of the disease. We recently reported that specific Killer Inhibitory Receptors (KIR) present on NK cells are related to a decreased ability to control herpesviruses infection [24], and it may be hypothesized that individuals with an immune response not capable of controlling infectious replication might be more susceptible to infection-related tumor development.

Any consideration about the possible role of antibiotic therapy in treating the neoplasm cannot be drawn, as the antibiotic treatment was started when the tumor had been surgically excised.

Studies of more patients would be needed to clarify the role of pathogens in PCALCL development.

\section{Abbreviations}

PCALCL: Primary cutaneous anaplastic large-cell lymphoma;

CTCLs: Cutaneous T cell lymphomas; HHV8: Human herpesvirus 8;

EBV: Epstein-Barr virus; MCD: Multicentric Castleman's Disease; PEL: Primary Effusion Lymphomas; PBMCs: Peripheral blood mononuclear cells.

\section{Competing interest}

The authors declare that they have no competing interests.

\section{Authors' contributions}

$A B$ contributed to: study concept and design, acquisition of data (clinical features), analysis and interpretation of data, drafting of the manuscript. EC contributed to: study concept and design, acquisition of data (HHV8 
analyses), analysis and interpretation of data, drafting of the manuscript. DDL contributed to: study concept and design, analysis and interpretation of data. AS contributed to: acquisition of data (clinical parameters, surgery), analysis and interpretation of data. PP contributed to: surgery, analysis and interpretation of data. SS contributed to: acquisition of data (Chlamydia analyses), interpretation of data. CC contributed to: study concept and design, acquisition of data (Chlamydia analyses), analysis and interpretation of data, drafting of the manuscript. AV contributed to: study concept and design, acquisition of data (clinical and histological features), analysis and interpretation of data. All authors read and approved the final manuscript.

\section{Acknowledgment}

We thank Dr Valentina Talarico for her excellent technical assistance.

\section{Author details}

'Department of Medical Sciences, Section of Dermatology, University of Ferrara, Via Savonarola 9, 44121 Ferrara, Italy. ${ }^{2}$ Department of Medical Sciences, Section of Microbiology, University of Ferrara, Ferrara, Italy. ${ }^{3}$ Department of Ophthalmology, University of Ferrara, Ferrara, Italy. ${ }^{4}$ Department of Medical Sciences, Section of Infectious Diseases, University of Ferrara, Ferrara, Italy.

Received: 4 June 2013 Accepted: 4 July 2013

Published: 7 October 2013

\section{References}

1. Mirvish ED, Pomerantz RG, Geskin LJ: Infectious agents in cutaneous T-cell lymphoma. J Am Acad Dermatol 2011, 64:423-431.

2. Miyashita N, Ouchi K, Kishi F, Tabuchi M, Tsumura N, Bannai H, Iwata S, Tanaka T, Oka M: Rapid and simple diagnosis of Chlamydophila pneumoniae pneumonia by an immunochromatographic test for detection of immunoglobulin M antibodies. Clin Vaccine Immunol 2008, 15:1128-1131.

3. Ponzoni M, Ferreri AJ, Guidoboni M, Lettini AA, Cangi MG, Pasini E, Sacchi L, Pecciarini L, Grassi S, Dal Cin E, Stefano R, Magnino S, Dolcetti R, Doglioni C: Chlamydia infection and lymphomas: association beyond ocular adnexal lymphomas highlighted by multiple detection methods. Clin Cancer Res 2008, 14:5794-5800.

4. Abrams JT, Balin BJ, Vonderheid EC: Association between Sezary T cellactivating factor, Chlamydia pneumoniae, and cutaneous T cell lymphoma. Ann N Y Acad Sci 2001, 941:69-85.

5. Gao SJ, Kingsley L, Li M, Zheng W, Parravicini C, Ziegler J, Newton R, Rinaldo CR, Saah A, Phair J, Detels R, Chang Y, Moore PS: KSHV antibodies among Americans, Italians and Ugandans with and without Kaposi's sarcoma. Nat Med 1996, 2:925-928.

6. Gambus G, Bourboulia D, Esteve A, Lahoz R, Rodriguez C, Bolao F, Sirera G, Muga R, del Romero J, Boshoff C, Whitby D, Casabona J: Prevalence and distribution of HHV-8 in different subpopulations, with and without HIV infection, in Spain. AIDS 2001, 15:1167-1174.

7. Suchankova A, Stankova M, Roubalova K, Vandasova J, Bruckova M: Seroprevalence of HHV 8 antibodies among the general population and HIV positive persons in the Czech Republic. J Clin Virol 2003, 28:70-76.

8. Wen KW, Damania B: Kaposi sarcoma-associated herpesvirus (KSHV): molecular biology and oncogenesis. Cancer Lett 2010, 289:140-150.

9. Chakraborty S, Veettil MV, Chandran B: Kaposi's Sarcoma Associated Herpesvirus Entry into Target Cells. Front Microbiol 2012, 3:6.

10. Caselli E, Fiorentini S, Amici C, Di Luca D, Caruso A, Santoro MG: Human herpesvirus 8 acute infection of endothelial cells induces monocyte chemoattractant protein 1-dependent capillary-like structure formation: role of the IKK/NF-\{kappa\}B pathway. Blood 2007, 109:2718-2726.

11. Contini C, Grilli A, Badia L, Guardigni V, Govoni M, Seraceni S: Detection of Chlamydophila pneumoniae in patients with arthritis: significance and diagnostic value. Rheumatol Int 2011, 31:1307-1313.

12. BLAST program. http://www.ncbi.nlm.nih.gov/BLAST.

13. Kempf W, Pfaltz K, Vermeer MH, Cozzio A, Ortiz-Romero PL, Bagot M, Olsen E, Kim YH, Dummer R, Pimpinelli N, Whittaker S, Hodak E, Cerroni L, Berti E, Horwitz S, Prince HM, Guitart J, Estrach T, Sanches JA, Duvic M, Ranki A, Dreno B, Ostheeren-Michaelis S, Knobler R, Wood G, Willemze R: EORTC, $I S C L$, and USCLC consensus recommendations for the treatment of primary cutaneous CD30-positive lymphoproliferative disorders: lymphomatoid papulosis and primary cutaneous anaplastic large-cell lymphoma. Blood 2011, 118:4024-4035.

14. Linnemann T, Gellrich S, Lukowsky A, Mielke A, Audring H, Sterry W, Walden P: Polyclonal expansion of T cells with the TCR $V$ beta type of the tumour cell in lesions of cutaneous T-cell lymphoma: evidence for possible superantigen involvement. Br J Dermatol 2004, 150:1013-1017.

15. Samimi S, Benoit B, Evans K, Wherry EJ, Showe L, Wysocka M, Rook AH: Increased programmed death-1 expression on CD4+ T cells in cutaneous T-cell lymphoma: implications for immune suppression. Arch Dermatol 2010, 146:1382-1388.

16. Ferreri AJ, Ponzoni M, Guidoboni M, De Conciliis C, Resti AG, Mazzi B, Lettini AA, Demeter J, Dell'Oro S, Doglioni C, Villa E, Boiocchi M, Dolcetti R: Regression of ocular adnexal lymphoma after Chlamydia psittacieradicating antibiotic therapy. J Clin Oncol 2005, 23:5067-5073.

17. Contini C, Seraceni S, Carradori S, Cultrera R, Perri P, Lanza F: Identification of Chlamydia trachomatis in a patient with ocular lymphoma. Am J Hematol 2009, 84:597-599.

18. Nagore E, Ledesma E, Collado C, Oliver V, Perez-Perez A, Aliaga A: Detection of Epstein-Barr virus and human herpesvirus 7 and 8 genomes in primary cutaneous T- and B-cell lymphomas. Br J Dermatol 2000, 143:320-323.

19. Herne KL, Talpur R, Breuer-McHam J, Champlin R, Duvic M: Cytomegalovirus seropositivity is significantly associated with mycosis fungoides and Sezary syndrome. Blood 2003, 101:2132-2136.

20. Uldrick TS, Whitby D: Update on KSHV epidemiology, Kaposi Sarcoma pathogenesis, and treatment of Kaposi Sarcoma. Cancer Lett 2011, 305:150-162.

21. Gantt S, Casper C: Human herpesvirus 8-associated neoplasms: the roles of viral replication and antiviral treatment. Curr Opin Infect Dis 2011, 24:295-301

22. Chiu B, Viira E, Tucker W, Fong IW: Chlamydia pneumoniae, cytomegalovirus, and herpes simplex virus in atherosclerosis of the carotid artery. Circulation 1997, 96:2144-2148.

23. Swanborg RH, Whittum-Hudson JA, Hudson AP: Human herpesvirus 6 and Chlamydia pneumoniae as etiologic agents in multiple sclerosis - a critical review. Microbes Infect 2002, 4:1327-1333.

24. Rizzo R, Gentili V, Casetta I, Caselli E, De Gennaro R, Granieri E, Cassai E, Di Luca $D$, Rotola A: Altered natural killer cells' response to herpes virus infection in multiple sclerosis involves KIR2DL2 expression. J Neuroimmunol 2012, 251:55-64.

\section{doi:10.1186/1750-9378-8-41}

Cite this article as: Borghi et al:: Detection of Chlamydophila pneumoniae and human herpesvirus 8 in primary cutaneous anaplastic large-cell lymphoma: a case report. Infectious Agents and Cancer 2013 8:41.

\section{Submit your next manuscript to BioMed Central and take full advantage of:}

- Convenient online submission

- Thorough peer review

- No space constraints or color figure charges

- Immediate publication on acceptance

- Inclusion in PubMed, CAS, Scopus and Google Scholar

- Research which is freely available for redistribution 